\title{
What is an Infinite Regress Argument?
}

\section{Claude Gratton University of Nevada-Las Vegas}

\begin{abstract}
I describe the general structure of most infinite regress arguments; introduce some basic vocabulary; present a working hypothesis of the nature and derivation of an infinite regress; apply this working hypothesis to various infinite regress arguments to explain why they fail to entail an infinite regress; describe a common mistake in attempting to derive certain infinite regresses; and examine how infinite regresses function as a premise.
\end{abstract}

Résumé: Je décris la structure générale de la plupart des arguments à régression infinie; introduis un vocabulaire de base; presente une hypothèse de travail sur la nature d'un type de régression et sur sa déduction; applique cette hypothèse de travail à divers arguments à régression infinie pour expliquer pourquol certaines régressions infinies ne s'ensuivent pas logiquement; décris une erreur courante dans les tentatives de déduire certaines régressions infinies; examine comment des régressions infinies jouent le rôle de prémisse.

Keywords: infinite regress, regress formula, triggering statement, output, vicious regress, benign regress, superfluous infinite regress, infinite regress of recurring problems and solutions

My goal in this paper is to identify and clarify some fundamental characteristics of most infinite regress arguments. ${ }^{1}$ Knowledge of these characteristics should facilitate our construction and assessment of these arguments. ${ }^{2}$

The core of an infinite regress argument is a complex argument typically consisting of at least two subordinate arguments: (a) the derivation of an infinite regress, and (b) the use of that regress, often along with other premises, to establish a further conclusion. Most infinite regress arguments also include a third subordinate argument showing that the conclusion obtained by means of the two core arguments is unacceptable (e.g. a false statement). The fundamental characteristics I am about to discuss pertain to these three types of subordinate arguments.

\section{The general structure of infinite regress arguments}

In this section I will present an example that is representative of most infinite regress arguments, then introduce some basic vocabulary that will facilitate the discussion of these arguments. I will also diagram the general structure of an 
infinite regress argument in order to locate more clearly the three types of subordinate arguments found in an infinite regress argument.

The following infinite regress argument from Ryle illustrates the typical derivation and use of an infinite regress.

According to the [intellectualist] legend, whenever an agent does anything intelligently, his act is preceded and steered by another internal act of considering a regulative proposition appropriate to his practical problem.... Must we then say that for the hero's reflections how to act to be intelligent he must first reflect how best to reflect how to act? The endlessness of this implied regress shows that the application of the criterion of appropriateness does not entail the occurrence of the process of considering this criterion....

To put it quite generally, the absurd assumption made by the intellectualist legend is this, that a performance of any sort inherits all its title to intelligence from some anterior internal operation of planning what to do. Now very often we do go through such a process of planning what to do.... The regress is infinite, and this reduces to absurdity the theory that for an operation to be intelligent it must be steered by a prior intellectual process. ${ }^{3}$

This passage is representative of many infinite regress arguments in that Ryle does not state exactly what entails the infinite regress. I name any statement or combination of statements a regress formula or a formula if it entails or is intended by its author to entail an infinite regress. A regress formula takes the form of one (or more) universally quantified statements which can be repeatedly instantiated. Each instantiation of a regress formula is triggered by a statement, which is sometimes omitted on account of its obviousness. I will call such statements, triggering statements. The most plausible and succinct formulation of the regress formula in Ryle's argument that serves my present purpose is, "Every intelligent act is preceded by an intelligent act." It is derived from the explicit premise that every intelligent performance (i.e. act) is preceded by intelligent planning, and from the implicit premise that every intelligent planning is an intelligent performance (i.e., act). The first triggering statement might be, "Act, is intelligent."

The infinite regress launched by the conjunction of a regress formula and its triggering statement consists of an infinitely long conjunction of statements. In the Ryle example, these statements are, "Intelligent act ${ }_{1}$ is preceded by intelligent act ${ }_{2}$," "Intelligent act $t_{2}$ is preceded by intelligent act ${ }_{3}$ " "Intelligent act ${ }_{3}$ is preceded by intelligent act 4 ," etc.

Ryle's regress argument also illustrates the most common function of an infinite regress: the refutation of a statement that entails an infinite regress. He states that the regress "reduces to absurdity" the theory that entails the infinite regress. Such refutations occur whenever an infinite regress entails a statement that is then shown to be false. Such an infinite regress is a vicious.

A typical infinite regress argument does not state precisely why its regress is vicious. Ryle's argument is a case in point. Here is one plausible reconstruction of that part of his regress argument. Given the infinite regress, it follows that 
before we perform an intelligent act, we must first perform infinitely many intelligent acts. But since we cannot perform infinitely many intelligent acts, we cannot perform an intelligent act. This conclusion is false because we do perform some intelligent, which is entailed by Ryle's true statement, "very often we do go through such $a[n]$ [i.e. intelligent] process of planning what to do."

The structure of Ryle's argument is a variation on a general structure that I will now describe. The structure represents three subordinate arguments of the types that form the core of most infinite regress arguments, namely one in which an infinite regress is purportedly derived, one in which the conjunction of that regress and other premises purportedly entails a result, and one that purportedly shows that this result is unacceptable. I say "purportedly" because these subordinate arguments can be invalid in specific infinite regress arguments. I will assume in my general description, however, that all these subordinate arguments are valid.

\section{(1) Regress formula (to be refuted) \& (2) triggering statement}

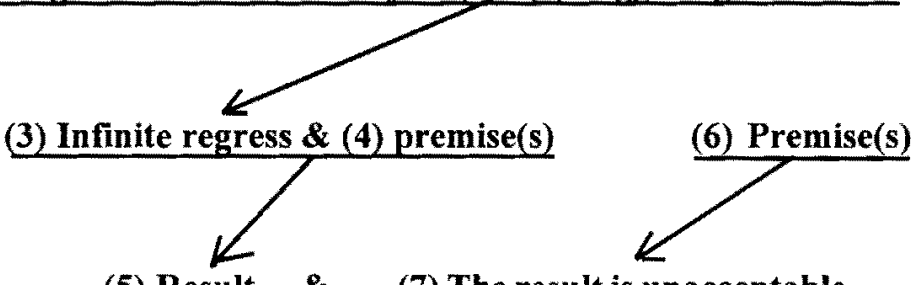

(5) Result \&

(7) The result is unacceptable.

(8) The regress formula is unacceptable.

The regress formula at (1) and the triggering statement at (2) together entail an infinite regress at (3). The expression at (3), "Infinite regress," does not denote a single statement but rather all the statements that constitute the infinite regress. The function of both the infinite regress at (3) and the premises at (4) is to entail a result at (5). The premises at (6) are independent of the derivation of the infinite regress and have the important function of showing that the result is unacceptable. A result is unacceptable if it is a false statement. ${ }^{5}$ (We will see in Section 4 that an infinite regress can be unacceptable for other reasons.) Assuming that the premises at (2), (4), and (6) are true, and that all the inferences are valid, the conflict resulting from the conjunction of (5) and (7) entails at (8) that the formula is unacceptable.

Of course, there can be variations on this general structure. As illustrated by Ryle's infinite regress argument, the regress formula itself might be derived: "Every intelligent act is preceded by an intelligent act" follows from the conjunction of "Every intelligent performance (i.e., act) is preceded by intelligent plan- 
ning," and "Every intelligent planning is an intelligent performance (i.e., act)." In some regress arguments a regress formula might consist of more than one universal statement. Sometimes an infinite regress is not derived but just assumed. For example, one might assume an infinite regress of causes, and attempt to show that such a regress is vicious in order to refute the existence of such regresses. ${ }^{6}$ The premises at (4) and (6) might be backed up by premises. The number of premises at (4) or (6) can also vary from argument to argument. Some infinite regresses do not even require premises corresponding to the premises at (4). There might be a succession of intermediate inferences between the conjunction of (3) and (4) and the result at (5).

In this introductory section I have used an infinite regress argument from Ryle to introduce some technical terms and to identify three central types of subordinate arguments within most infinite regress arguments. I located these argument-types in a diagram representing the general structure of an infinite regress argument. We can now proceed with a detailed examination of the first subordinate argument-type, in which an infinite regress is derived.

\section{A hypothesis about the nature of infinite regresses}

In this section, I identify a few fundamental aspects of the nature of an infinite regress by describing the derivation of a "classic" infinite regress. I do not aim to present a complete account of the nature of infinite regresses but rather a hypothesis about their nature. I will first present two paradigm cases of infinite regresses, and propose some terminology that will facilitate the discussion.

Our philosophical heritage provides us with the following two segments of paradigm cases of an infinite regress.

A(1): thing $\mathrm{g}_{2}$ is smaller than thing , thing $_{3}$ is smaller than thing ${ }_{2}$, thing ${ }_{4}$ is smaller than thing, ad infinitum.

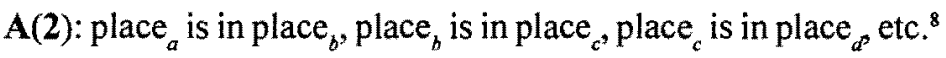

Regress A(1) contains the relation "smaller than", which relates terms named thing, , thing, , thing $_{3}$, thing ${ }_{4}$; regress A(2) contains the relation "in," which relates the terms named place, place $_{b}$, place, and place ${ }_{d f}$ (The numbers and letters following each named term are just one way of differentiating each named term.) Each relation combined with its terms forms a relational statement. To designate a specific relational statement in a series of possibly infinitely many relational statements, I will use the expression, "step". For example, "thing is smaller than thing," and "thing, is smaller than thing " are the first two steps of regress $A(1)$, and "place is in place " is the third step of regress A(2). Since the order of the terms in a series of steps is important, I will sometimes describe a step in a regress as an "ordering."

A fundamental aspect of the two paradigm cases is that their steps comprise a series from which one can construct a regress formula that entails the remainder of the intended infinite regress: for regress $A(1)$ the formula is "For any small 
thing there is a smaller thing"; for regress $\mathrm{A}(2)$ the formula "Every place is in a place."

In order to explain how a regress formula entails an infinite regress, I will refine the account of a regress formula given in Section 1. The expression "regress formula" designates any universal statement (or conjunction of universal statements) that in conjunction with a triggering statement generates the next new triggering statement and the next new step of a regress by means of a recursive procedure. I call the logical consequence of this conjunction an output. A regress formula is a recursive formula. In general, a formula or a procedure is recursive when it "can be applied to a starting point to get a certain result, and then re-applied to that result to get a further result, and so on. Adding one is a recursive procedure for generating the natural numbers from zero." ${ }^{\prime 9}$ The recursive procedure of regress formulas derives outputs by means of the rules of deductive logic.

I will illustrate this procedure with the regress formula, "Every place is in a place." The conjunction of that formula and a triggering statement, e.g., "There is a place ${ }_{a}$ entails the first output (in this case, a pair of statements):

(a) a new triggering statement, "There is a place ${ }_{b}$; and

(b) the first step of the regress, place ${ }_{a}$ is in place ${ }_{b}{ }^{10}$ From that first output there follows a new triggering statement, "There is a place,". The conjunction of that statement and the formula entails the second output: (a') a new triggering statement, "There is a place "; and

(b') the second step of the regress, place $e_{b}$ is in place $c^{\prime}$

The procedure is recursive because, just as the triggering statement in the first output and the formula together entail a new triggering statement in the second output, the triggering statement of each output ${ }_{(n)}$ and the formula together entail a new triggering statement in output ${ }_{(n+1)}$. Since a triggering statement and a step $p_{(n)}$ can be identical, " a more general description of the recursiveness of a regress formula is that each output ${ }_{(n)}$ and a regress formula together entail output ${ }_{(n+1)}$

It is because of this recursive process that the terms and relations of a regress are ordered. This order appears to be necessary if we contrast the following two series, in which " $\mathrm{P}_{a}$ ", " $\mathrm{P}_{b}$ ", etc., stand for "place ," "place,", etc.

$\mathbf{B}(1): \mathrm{P}_{a}$ is in $\mathrm{P}_{b} . \mathrm{P}_{b}$ is in $\mathrm{P}_{c} . \mathrm{P}_{c}$ is in $\mathrm{P}_{d}$, ad infinitum.

$\mathbf{B}(2): \mathrm{P}_{a}$ is in $\mathrm{P}_{b}, \mathrm{P}_{b}$ is in $\mathrm{P}_{c}, \mathrm{P}_{c}$ is in $\mathrm{P}_{d}$, ad infinitum. Only $B(1)$ is a segment of an infinite regress. The only relevant difference between $B(1)$ and $B(2)$, which explains why $B(2)$ is not a segment of an infinite regress, is that $\mathrm{B}(2)$ lacks the order from which one can construct a regress generating formula that, in conjunction with any output ${ }_{(n)}$, entails output ${ }_{(n+1)}$.

This contrast between a paradigm case of an infinite regress and a very similar series that is not an infinite regress suggests the following properties of an infinite regress. A series of steps forms a segment of an infinite regress only if (a) 
the steps are ordered in such a way that (b) it is possible to construct a recursive formula (c) whose output ${ }_{(n)}$ (consisting of a triggering statement and step ${ }_{(n)}$ ), together with that formula, entails output ${ }_{(n+1)}$ (consisting of a new triggering statement, and $\left.\operatorname{step}_{(n+1)}\right) .^{12}$

Conditions (a), (b), and (c) are not jointly sufficient for an infinite regress. ${ }^{13}$ First, though these conditions entail that there are infinitely many terms, they do not soundly establish that there are infinitely many, and so a necessary condition of a typical infinite regress is not satisfied. Secondly, some series satisfy these conditions without being infinite regresses. Any situation where I face a wall is one in which I face point $a$, I face point $b$, I face point $c$, etc.: $i \mathrm{~F} a, i \mathrm{Fb}, i \mathrm{Fc}$, etc.. Here we have (a) steps ordered in such a way that (b) it is possible to construct a recursive formula, "For any point that I face, I face a new point," (c) whose output ${ }_{(n)}$ together with that formula entail output ${ }_{(n+1)}$. Yet this series is intuitively not an infinite regress. ${ }^{14}$

Though conditions (a) (b) and (c) are not jointly sufficient, my hypothesis $\mathbf{H}$ is that they are individually necessary conditions of an infinite regress. I have provided sufficient evidence elsewhere to show that $\mathrm{H}$ is a reasonable working hypothesis. ${ }^{15}$

\section{Applications of the hypothesis}

I will illustrate the practical value of the working hypothesis $\mathrm{H}$ by showing how we can use it to determine whether an argument is an infinite regress argument.

G.C. Nerlich believes that Plato uses an infinite regress argument to argue that there is only a single Form for any thing that has a Form. ${ }^{16}$

Now God, whether because he willed or because some compulsion was laid upon him not to make more than one couch in nature, so wrought and created one only, the couch which really in itself is. But two or more such were never created by God and never will come into being. [...] Because [. . ] if he should make only two, there would again appear one of which they both would possess the form or idea, and that would be the couch that really is in and of itself, and not the other two. God $[\ldots]$ knowing this and wishing to be the real author of the couch that has real being and not of some particular couch, nor yet a particular cabinetmaker, produced it in nature unique. (Republic, $597 \mathrm{c})^{17}$

Neither Plato nor Nerlich states the first steps of the alleged regress, which would very likely resemble the following. (1) If two couches were made by God, there would arise only a single Form of the couch. (2) If three couches were made by God, there would arise only a single Form of the couch, and so on.

If I have correctly identified the first steps of the series, those steps are not a segment of an infinite regress. This series fails to satisfy the requirement that a recursive formula can be constructed from the ordered repetition of terms and relations. The formula that appears to be constructed from these first two steps would seem to be, "Given any number of couches made by God, there always 
arises only a single Form of the couch." However, this formula is not constructed from the order of the given steps because the formula is merely a generalization of either one of those steps, i.e., a generalization of either one of the given conditional statements. So the same formula can be constructed from any disordered combination of those "steps."

Another necessary condition that is not satisfied is that the formula is not recursive. For instance, the conjunction of the second step and the formula does not entail the third expected step: "If four couches were made by God, there would arise only a single Form," because step (3) could be, "If sixty couches were made by God, there would arise only a single Form of the couch." However, if this regress were ordered, the latter conditional statement would be step (59). So, the conjunction of output $t_{(n)}$ and the formula does not entail output ${ }_{(n+1)}$. Therefore, if I have correctly interpreted Plato's passage, there is no infinite regress in his argument.

Thus hypothesis $\mathrm{H}$ enables us to show that, and why, Nerlich is mistaken in believing that Plato has presented an infinite regress argument. ${ }^{18}$

Hypothesis $\mathrm{H}$ can also help us to determine whether a regress formula entails an infinite regress. For if the conjunction of such a regress formula and a triggering statement ${ }_{(n)}$ entails an output that does not contain triggering statement ${ }_{(n+1)}$, necessary for the entailment of the next step of an intended regress, then the formula does not entail the next new step, and so, the regress formula does not entail the regress.

Consider the following example:

If a proponent of Schools of Education were to argue that in order to qualify to teach, someone must teach you how to teach to teach and he, in turn, must be taught by someone how to teach to teach to teach, etc., then a [... ] a regress is created. ${ }^{19}$

The first three steps are, "Teacher, is taught how to teach by teacher ${ }_{2}$," "Teacher is taught how to teach by teacher ${ }_{3}$ " (and so, teacher ${ }_{2}$ is taught how to teach to teach); "Teacher is taught how to teach by teacher ${ }_{4}$ " (and so, teacher ${ }_{3}$ is taught how to teach to teach to teach), ad infinitum. We can construct the following regress formulas from the structure of these first three steps.

(1) Every teacher is taught by a teacher.

(2) Every teacher is taught by a distinct teacher.

(3) Every teacher is taught by a new teacher.

A superficial examination of these formulas suggests that each one entails the regress. However, only (3) does entail it. Formula (1) fails to entail the regress because it is possible for the formula to be true and to entail an output that does not contain the triggering statement necessary to entail the next new step of the regress. For example, it is possible that teacher ${ }_{(m)}$ is taught how to teach by teacher $_{(n+1)}$, and that the latter is self-taught. Formula (2) fails for similar reasons. For instance, it is possible that the formula is true, and that a finite number of 
teachers teach one another how to teach. Hence, there will come a point along the intended infinite regress where the conjunction of a triggering statement having the form, "There is a teacher ${ }_{(n)}$ " and the regress formula will not entail a new output containing the next triggering statement, "There is a teacher ${ }_{(n+1)}$ " and the next step, "Teacher ${ }_{(n)}$ is taught by teacher ${ }_{(n+1)}$," In contrast to the two preceding formulas, formula (3) does entail the regress because no such point is reached along the regress.

The preceding discussion illustrates that given steps of an intended regress do not provide enough information to construct a regress formula that entails the regress. ${ }^{20}$ In the next example we will see how the given steps of a purported regress conceal assumptions upon which each step rests, and I will use hypothesis $\mathrm{H}$ to illustrate how these assumptions can prevent the entailment of the intended regress. This discussion will further illustrate how steps of an intended regress can mislead us, and will provide a useful way of evaluating the derivation of an infinite regress when only a finite number of steps are given. The evaluation will be described in terms of the sufficient condition of each step.

William Poundstone has us imagine a situation where

[a] map is half as wide as the country it represents. A 1:2 map of the United States stretches from San Francisco to Kansas City, blanketing the mountain states. A map that big is itself a significant man-made [geographical] feature worthy of inclusion on all maps of the country. That means the $1: 2$ map must show itself. And the map on the map must contain a map of itself, and so on ad infinitum. ${ }^{21}$

The first two steps of the regress are (1) map of the U.S. includes map of the

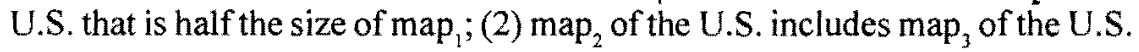
that is half the size of map ${ }_{2}$, and it is suggested that the regress extends in the same way. If we construct a regress formula exclusively from the structure of these first steps we obtain, "Each map of the U.S. contains map $_{(n+1)}$ of the U.S. that is half the size of $\operatorname{map}_{(n)}$ " "Though this formula does entail the intended regress, it it makes us overlook a crucial assumption of each step.

To identify this assumption I must first describe the assumptions of the first step. I will speak of them as the condition (i.e. the premises) sufficient for the first step of the intended regress.

C(1): Map 1 of the U.S. is man-made.

$C(2)$ : Map, is half the size of the U.S., and covers half the U.S..

C(3): $M a p_{1}$ is a significant geographical feature.

C(4): Whenever a man-made geographical feature is significant, map, includes it within map ${ }_{1}$, and it is half the size of map.

C(5): So, map of the U.S. includes within itself map $_{2}$ of the U.S. which is half the size of map.

In order go from these assumptions of the first step to assumptions of each step, I must make use of hypothesis $\mathrm{H}$. Given any infinite regress, it satisfies the conditions of $\mathrm{H}$. Take any specific sufficient condition of any step of any infinite 
regress. For example, given $\mathrm{H}$, and the infinite regress, place ${ }_{a}$ is in place ${ }_{b}$, place $_{b}$ is in place, ad infinitum, a specific sufficient condition of the step, place ${ }_{m}$ is in place $_{n}$, is,

D(1): There is a place ${ }_{m}: P_{m}$.

$\mathbf{D}(2)$ : If there is a place ${ }_{m}$, there is a place ${ }_{n}$, and $m$ is in $\mathrm{n}: \mathrm{P}_{m} \rightarrow\left(\mathrm{P}_{n} \& m \mathrm{In}\right)$.

Since all the conditions of $\mathrm{H}$ are satisfied, the conjunction of each output ${ }_{(n)}$ and a regress formula entails output ${ }_{(n+1)}$. Since it is always the same regress formula that generates each output, each triggering statement must satisfy the same conditions in order to trigger the formula. Consequently, each triggering statement must have the same logical form. Therefore, the generalization of any specific condition sufficient for any step of a regress (i.e., an instantiated regress formula and triggering statement) gives us the general conditions sufficient for all the steps of the infinite regress.

For example, the generalization of the specific condition $D$ sufficient for the step, $m$ is in $n$, is:

$\mathbf{E}(1)$ : There is a place: $:(\mathrm{Ex})(\mathrm{P} x)$.

$\mathbf{E}(2)$ : For any place, there is a place $e_{y}$, and $x$ is in $y:(x)\left(\mathrm{P}_{\mathrm{x}} \longrightarrow(\mathrm{E} y)\left(\mathrm{P}_{y} \& x \mathrm{l} y\right)\right)$. This generalization of $D$ gives us the general conditions sufficient for all the steps of the regress, place $e_{a}$ is in place ${ }_{b}$, place $_{b}$ is in place ${ }_{c}$, ad infinitum.

So, if $\mathrm{C}(1)$ to $\mathrm{C}(4)$ entails the first step $\mathrm{C}(5)$, a generalization of each premise should entail the general condition sufficient for all the steps of the intended regress of successively smaller maps:

$F(1)$ : Map $_{(n)}$ of the U.S. is man-made.

$F(2):$ Map $_{(n)}$ of the U.S. is half the size of what it represents.

$F(3): M_{i n}$ of the U.S. is a significant geographical feature.

$\mathbf{F}(4)$ : Whenever a man-made geographical feature is significant, map $_{(n)}$ includes it within map (n) , and it is half the size of $\operatorname{map}_{(n)}$.

F(5): So, each map $_{(n)}$ of the U.S. includes map ${ }_{(n+1)}$ of the U.S. which is half the size of $\operatorname{map}_{(n)}$

Though argument $\mathrm{C}$ is valid, $\mathrm{F}$ is not. For as the regress extends, map , becomes $(1 / 2)$ of the size of map ${ }_{(n-1)}$, and $(1 / 2)^{\text {th }}$ the size of the U.S., and due to this gradual decrease in size, the regress will eventually reach a step $(n)$ where the size of a small map ${ }_{(x)}$ is not a significant man-made geographical feature (and so $F(3)$ is false). Map ${ }_{(x)}$ will thus fail to satisfy the condition stated in $\mathrm{F}(4)$, and consequently, no new map will be entailed, and so, the regress will not extend beyond that point. Hence, the premises of $F$ do not entail the intended regress. But $F(5)$ does entail the intended regress, and if the premises of $F$ entailed the regress formula at $F(5)$, they would also entail the infinite regress. Consequently, the premises of $F$ do not entail $F(5)$. Therefore, if we construct the regress formula $F(5)$ exclusively from the structure of the given first steps, we overlook assumptions upon which rest each step of the intended regress, and in this particular case they are assumptions that prevent the entailment of the regress. 
Whenever we overlook the premises from which a regress formula is supposed to follow, or whenever we overlook the general conditions sufficient for each step, we are vulnerable to committing the mistake described in the above quoted passage. This kind of mistake often results when we construct a regress formula exclusively from the structure of the first given steps.

The preceding discussion illustrates how we can evaluate the derivation of an infinite regress in terms of the sufficient condition of each step of an infinite regress. It also illustrates that when there are changes in the terms of an intended regress, the regress might not be entailed. (What makes a change relevant will vary from argument to argument.) I will continue to speak in terms of such sufficient conditions with the next example, and examine a different way in which changes in the terms of a purported regress can prevent the entailment of a regress.

In the following argument, Colin McGinn is arguing that the purpose of human life does not depend on the existence of some supernatural being.

It seems to be very tempting to feel, as a matter of metaphysical exigency, that it [human life] must have some point-that there must be something external to it that give it a point [i. e., a purpose]. And here religious ideas are commonly invoked: it is either the existence of God that gives human life a point, or the fact of some more or less supernatural previous or subsequent life. These extramortal entities are supposed to inject a point into our life that it would otherwise wholly lack. Now the essential thing to notice about these point-conferring beings is that they are themselves instances of kinds of life, either divine or supernatural in some other way. And the idea is that they are in some way 'unmeant meaners': they give a point to our lives without themselves needing to have a point conferred upon theirs. But now the flaw should be apparent: why should these lives be allowed to have meaning intrinsically while our lives are required to have meaning conferred extrinsically upon them? If the lives of some beings must carry meaning within themselves, as God's is supposed to, or the selves of the afterlife, them why can't our lives achieve that now? Clearly it is no use to postulate further lives-a God for God or an afterlife for our afterlife - on pain of an infinite regress. ${ }^{22}$

I will address only the issue pertaining to the infinite regress. The first steps of the regress are: (1) God gives meaning to humans; (2) God $_{2}$ gives meaning to $\mathrm{God}_{1}$; (3) God gives meaning to $\mathrm{God}_{2}$, etc.. We should first note that there is a radical change in the terms: they go from humans to Gods. (This change differs from that of the preceding example in which all the terms have the name of the class to which they all belong: they are all maps.) This should signal to us that there could be some problems in attempting to derive the intended regress.

McGinn attempts to derive the regress as follows. When he raises the rhetorical question, "why should these lives be allowed to have meaning intrinsically while our lives are required to have meaning conferred extrinsically upon them?"23 he implicitly appeals to the principle that like cases should have like consequences. The likeness is with respect to the property of being a kind of life. 
His rhetorical question is another way of asserting that the supernatural beings require to have meaning conferred extrinsically upon them just as human lives because they are a kind of life just like humans. An infinite regress is supposed to follow.

However, even if we granted that humans and Gods are somehow "kinds of life," there are two reasons why it is hasty to conclude that an infinite regress is entailed. First, McGinn is assuming that even if humans and Gods are radically different kinds of life, the presence of life in humans, which is a sufficient condition for attributing some property $\mathbf{x}$ to humans, remains a sufficient condition for attributing $\mathbf{x}$ to God. There are many counter-examples against that assumption; e.g., human life is mortal, but Godly life is by definition immortal, and so the mortality of humans cannot be attributed to God. Thus, if life in humans is a sufficient condition for attributing some extrinsically conferred meaning to humans, it does not follow that life remains a sufficient condition for attributing such a property to God. Therefore, even if one grants the first step that God, gives purpose to humans, the second step that God gives purpose to God does $_{1}$ not logically follow.

Secondly, just as there are relevant differences between humans and Gods, there can be relevant differences among the Gods themselves. For example, it is possible that $\mathrm{God}_{2}$ is a greater being who can by Itself confer purpose onto Itself.

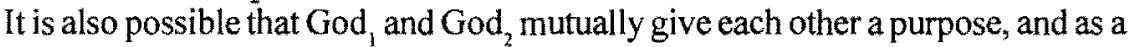
result it does not logically follow that there is some $\mathrm{God}_{3}$ that gives purpose to God $_{2}$. Therefore, even if it is granted that some $\operatorname{God}_{(n+1)}$ gives purpose to $\operatorname{God}_{(n)}$, it does not follow that some $\operatorname{God}_{(n+2)}$ gives purpose to $\operatorname{God}_{(n+1)}{ }^{24}$

The examples from McGinn and Poundstone illustrate the importance of determining whether there are any significant changes in the terms of a regress as the regress extends. This is important because if the terms at step ${ }_{(n)}$ change, then the conditions that were sufficient for the preceding steps might no longer remain sufficient for step ${ }_{(n+1)}$. We can describe the same idea in terms of hypothesis $\mathrm{H}$ : if the terms at step ${ }_{(m)}$ change significantly, then the next output might not contain the triggering statement necessary to entail the next new step of an intended infinite regress.

The differences or changes occurring in the terms of a purported regress as it extends are usually not stated explicitly, and if we fail to attend to these changes we are more vulnerable to "see" infinite regresses where there are none. Such a mistake is committed more often than we realize. For example, a few philosophers interpret the following passage by Wittgenstein as entailing an infinite regress, even though the context of this passage suggests that Wittgenstein himself does not believe that there is a regress. ${ }^{25}$

239. How is he to know what colour he is to pick out when he hears 'red'? Quite simple: he is to take the colour whose image occurs to him when he hears the word. But how is he to know which colour it is 'whose image occurs to him'? Is a further criterion needed for that? ${ }^{26}$ 


\section{Claude Gratton}

Only the first step is given: red coloured objects are picked out (or identified) by means of a red coloured image. The question in the passage, "Is a further criterion needed for that?" is another way of asking whether the red coloured image needs to be identified by means of another red coloured entity. Whether the regress is intended to extend exclusively in the realm of red images beyond the first step does not affect my central point, for the terms of the first step change from physical objects to images. This should signal to us that the regress might not be entailed. A coloured image is a mental object. But do the conditions sufficient for having red objects identified by means of red images remain sufficient for having such red images identified by some further red entity? It seems possible that some difference in the mental world of images could prevent those conditions from remaining sufficient when applied to red images. Of course this does not show that there is no regress, but it does show that insufficient information has been provided to conclude that an infinite regress extends beyond the first step.

If we were to construct a regress formula from the structure of a succession of steps similar to the first step, e.g." "nothing can be identified except by comparison with an image"27 two consequences could follow. First, we would probably overlook that the regress extends from the world of physical objects to the mental world of images, and thus probably overlook some relevant differences that could prevent the entailment of the regress. In more general words, the differences could prevent some condition sufficient for ste $p_{(n)}$ from continuing to be sufficient for $\operatorname{step}_{(n+1)}$. Secondly, such a formula would conceal a false assumption underlying all the steps beyond the first step. These steps rest on the general assumption that if $y$ is to serve as a criterion to identify $x, y$ must itself be identified in a similar way. Here is a counter-example against the assumption. The standard metre serves as a criterion to measure metre-length measuring instruments, but the standard metre does not have to be measured by some other standard metre even though the standard metre is a metre-length measuring instrument. $^{28}$

Some philosophers disregard the changes occurring in terms as an alleged regress extends even when they state them explicitly. Here is an example from Donagan: "Once you concede [...] that particulars and universals need a further universal, and an anomalous one at that, to relate them, you cannot deny that that further universal requires yet a further one, and so on ad infinitum." ${ }^{\text {"9 }}$ After accepting the first step it is assumed that merely being a universal at each step suffices to entail the next step. But the evaluation of the generation of this regress would require a clarification of the meaning of "anomalous" in order to determine whether the second universal still requires a universal just as the first one requires a universal.

The passages from Donagan and McGinn suggest that they implicitly appeal to the general idea that similar cases have similar consequences, such that the 
acceptance of a few successive steps compels us to infer that there is an endless succession of similar steps. But as we have observed, this similarity must be with respect to relevant conditions, and the generalization of those conditions must be sufficient to entail all the other steps of an intended regress. The mere fact that we accept a few steps whose terms are all alike in some respect (e.g. teacher is taught by teacher ${ }_{2}$, teacher ${ }_{2}$ is taught by teacher ${ }_{3}$ ) does not satisfy these two necessary conditions, and so the acceptance of those steps should not logically compel us to infer that there is an infinite regress.

I have examined examples to illustrate that if we fail to attend to changes that occur in some terms in the given steps of an alleged regress, we can mistakenly conclude that there is an infinite regress. Whenever we note such changes, it is appropriate to raise the guiding questions, "Do the conditions sufficient for the given steps remain sufficient for all the other steps of the regress?" It is also prudent to raise this question even if one's formula constructed from the pattern of those steps entails the intended regress, for as we have seen, the regress formula might not be based on the assumptions of the steps of the intended regress.

My use of hypothesis $H$ has also helped us to see the risks of constructing a regress formula exclusively from the structure of given steps of a regress, and it has allowed us to analyze the derivation of an infinite regress in terms of the sufficient conditions of each step.

The discussion of this section can help to provide the justification to what Passmore calls a privileged term: an "infinite regress can be evaded, temporarily at least, by claiming privilege for the first step in an alleged regress. ${ }^{30}$ However, a privilege need not limit itself to a first step, it can be granted anywhere along a regress when there is justification. Such a justification consists of showing that a condition sufficient for some step $p_{(n)}$ of an intended regress is not sufficient for $\operatorname{step}_{(n+1)}{ }^{31}$ For example, someone could argue that explaining why anything exists by reference to God's existence does not involve a regress because "the existence of God does not require explanation in the sense in which the other things requires explanation." ${ }^{32}$ The absence of such a requirement would be based on a relevant difference between God's existence and the existence of all the other things.

\section{Logical functions of in finite regresses}

We have investigated certain aspects of the nature and derivation infinite regresses. We will now examine how an infinite regress functions as a premise in infinite regress arguments. We should first bear in mind that not all infinite regresses have an argumentative function. For some infinite regresses are not used to prove anything. For example, the statement " $\mathrm{S}$ is true" entails the infinite regress, (1) $\mathrm{S}$ is true; (2) ( $\mathrm{S}$ is true) is true; (3) ((S is true) is true) is true, etc. For it is impossible for (1) to be true and (2) to be false; it is impossible for (2) to be true and 
(3) to be false, etc. This regress is generally not used to prove any statement. What interests us, however, are the regresses used in arguments.

Infinite regresses are typically derived from one or more statements, and the function of most infinite regresses is to refute at least one of those statements. As stated in Section 1, these refutations occur whenever an infinite regress entails an unacceptable result such as a false statement; and such an infinite regress is vicious. Most infinite regresses arguments thus function like a reductio ad absurdum argument. Ryle's regress argument against the intellectualist legend, discussed in Section 1, illustrates this point. In the next example it is argued that some form of highest political power is necessary in order to settle political issues with finality. "It seems clear that every political society involves the presence of supreme power .... For otherwise all power would be subordinate and this supposition involves the absurdity of a series of superiors and inferiors $a d$ infinitum. ${ }^{133}$ Let us grant the intended regress of infinitely many successively higher levels of governments. A law passed at any level of government would have to be passed by infinitely many higher levels of government, and so the regress entails that no law would ever be passed. Since laws are passed, the regress entails a false statement, and thus it entails an unacceptable result. Hence, the regress is vicious, and consequently refutes the regress formula that every political power is subordinate to a political power.

A result entailed by an infinite regress can be unacceptable for reasons other than the fact that it is a false statement. For example, most infinite regresses entail that there are infinitely many entities. ${ }^{34}$ If in a particular context such a quantity involves a multiplication of entities beyond necessity, and if one believes a rule (Occam's Razor) according to which entities are not to be multiplied beyond necessity, then the regress entails a result that conflicts with a rule. Hence, the result is unacceptable. So an infinite regress is also vicious whenever it entails a result that conflicts with a statement or a rule that we are unwilling to abandon.

It might be objected that by using the pronoun "we," I relativize an unacceptable result, for a result can be unacceptable relative to one audience but acceptable to a different audience. This does not entirely relativize my notion of viciousness. For I state that a result is unacceptable if it is false or if it conflicts with a rule or statement that we are unwilling to abandon. Viciousness is not entirely relativized because if an infinite regress entails a false statement, then the regress is vicious-regardless of whether an audience is aware that a false statement is entailed. The relativized portion of my account helps to explain why there can be disagreement in establishing the viciousness of some infinite regresses: some people hold certain beliefs that conflict with the result entailed by an infinite regress, while others do not hold those beliefs.

My general account of the viciousness of infinite regresses applies also to infinite regresses of recurring problems and solutions. The lack of space allows 
me only a very condensed characterization of these regresses ${ }^{35}$ The first step to be taken is to raise a certain problem; the second step consists in providing a solution to that problem. However, it is immediately shown that the type of problem raised at the first step may be raised once more. ${ }^{36}$ This is the third step. The fourth step leads to the solution of this problem along the lines provided by the second step, and so on ad infinitum. ${ }^{37}$ There are at least two ways in which problems recur in such regresses. In some cases a solution purportedly generates the same kind of problem it is supposed to solve. In other cases a solution does not generate a problem but rather purportedly fails to prevent the recurrence of the same kind of problem.

Both kinds of regresses are vicious because, given certain assumptions, they entail an unacceptable consequence. These regresses first arise from an assumption that a solution will solve a problem. If a regress consists of successive applications of a solution that generates the same kind of problem it is supposed to resolve, then such a regress entails the statement that solution ${ }_{(n)}$, where " $n$ " is a natural number, generates problem ${ }_{(n+1)}$. If we believe that a solution is successful or acceptable only if it does not generate the same kind of problem it is supposed to resolve, then the regress entails a statement that conflicts with a belief. If we do not abandon the belief, then the regress entails an unacceptable statement, and so the regress is vicious. It follows that the assumption from which the regress arises is unacceptable, and is thus refuted. The same kind of reasoning applies to regresses consisting of successive applications of solutions that fail to prevent the recurrence of the same kind of problem. ${ }^{38}$ The only significant difference in such cases is that one would hold a belief that a solution is successful or acceptable only if it prevents the recurrence of the same kind of problem it is supposed to resolve. Thus, regresses of recurring problems and solutions are vicious because they also entail unacceptable consequences, and my explanation of their viciousness shows that arguments using such regresses also function like a reductio ad absurdum argument. ${ }^{39}$

My account of the viciousness of regresses is very general, and any attempt to make it more specific and detailed would require a discussion of the content of premises (5) and (6) in the diagram in Section 1. Since the content would tend to vary from argument to argument, such a discussion would not help us to assess infinite regress arguments in general.

However, Romane Clark believes that he can provide a more specific explanation of the viciousness of some infinite regresses without having to discuss the content of these arguments. ${ }^{40} \mathrm{His}$ explanation applies to all infinite regresses that follow from a statement having the form $(x)(\mathrm{F} x \rightarrow(\mathrm{E} y)(\mathrm{F} y \& x \mathrm{R} y)$, and where $\mathrm{R}$ is an asymmetric and transitive relation. The explanation goes as follows. Given this formula, the asymmetry and transitivity of $R$, and the (triggering) statement that some particular $a$ is categorically $\mathrm{F}$, an infinite regress logically follows. ${ }^{41}$ Clark believes that such a formula shows that "nothing is $F$ unless [it is] a member 
of" the regress. ${ }^{42}$ When "there is no independent existence proof" for the infinite succession of similar elements, whatever is $F$ is at most only conditionally $F$; in other words, nothing can be said to be categorically $\mathrm{F}$. But the triggering statement is $\mathrm{F} a$, and "something is categorically $\mathrm{F}$ just in case it is $\mathrm{F}$ but not only conditionally so." ${ }^{.43}$ Since the regress formula and the categorical statement that Fa together entail the contradiction that a is both categorically and not categorically $F$, the infinite regress is vicious. ${ }^{44}$

Suppose that Clark is right that there is a contradiction here. This would show that the regress is vicious. Clearly it would be so on the general account I have given of viciousness. For a contradiction is a falsehood, and hence an unacceptable result.

But is Clark right that there is a contradiction here? I believe not. First, it is obvious that it is possible to assign the truth-value of truth to (categorical) $\mathrm{F} a$ and to all the instantiations of the regress formula $(x)(\mathrm{F} x \longrightarrow(\mathrm{E} y)(\mathrm{F} y \& x \mathrm{R} y))$, even if there is no independent existence proof of the infinite regress. Therefore, $\mathrm{F} a$ and the regress formula are consistent. Two consistent statements do not entail a contradiction. Therefore, $\mathrm{F} a$ and the regress formula do not entail a contradiction.

Secondly, if a formula having the structure $(x)(\mathrm{F} x \rightarrow(\mathrm{E} y)(\mathrm{F} y \& x \mathrm{R} y))$ and a triggering statement together entailed a contradiction, then all nonvicious regresses entailed by formulas with the same structure would be vicious. For example, from the conjunction of the formula, "For any natural number there is greater natural number", i.e., $(x)(\mathrm{N} x \rightarrow(\mathrm{E} y)(\mathrm{N} y \& y \mathrm{G} x))$, and the triggering statement, "There is the natural number 1 ," there follows an infinite regress that is not vicious. But according to Clark's way of explaining viciousness, it would be vicious.

Though most infinite regresses entail an unacceptable result, it is generally overlooked that some infinite regresses function as a premise without entailing any unacceptable result. Such a regress is benign. The only structural difference between an argument that uses a vicious regress and one that uses a benign regress is that the latter does not include a sub-argument showing that the regress entails an unacceptable result.

Benign infinite regresses are less common than vicious infinite regresses, but they do exist. ${ }^{45}$ For example, Sextus Empiricus makes use of a benign regress to argue that no sage deserves credence.

And if anyone shall demand that we should ... simply believe the man that is more sagacious than all others, then ... this man will not deserve credence. For inasmuch as sagacity is liable to a great, indeed almost incalculable, advance or decline in intensity, we assert that it is possible for another man to arise who is more sagacious than this man who, we say, is more sagacious than those of the past and present. So then, just as we are requested to believe the man who is now said to be wiser than those of the present and the past because of his 
sagacity, so it is still more proper to believe his successor in the future who will be more sagacious than he. And when that successor has arisen, then it is right to expect that yet another will arise more sagacious than he, and so on ad infinitum. Nor is it evident whether all these men will agree with one another or contradict one another. And consequently, even when one of them is acknowledged to be more sagacious than those of the past and present, seeing that we are unable to affirm positively that no man will be more clever than he (this being non-evident), we shall always have to wait for the judgement of the more sagacious man of the future, and never give our assent to this superior person. ${ }^{46}$

The implicit regress formula, "For any wise man there is a wiser man," and a triggering statement such as "Socrates is wise" together entail an infinite regress of successively wiser men. This regress entails that there is no wisest man. Assuming that we should believe only the wisest man, we should not believe any wise man. Since Sextus uses the infinite regress to establish a final conclusion without having the regress entail any unacceptable result, the regress is benign.

In the next example, Anaxagoras uses a benign regress to argue that there is no smallest thing in the universe. ${ }^{47}$ The regress formula is, "of the small ... there is always a smaller"; granting that there is a small thing, there follows an infinite regress of successively smaller things; and from that regress it follows that there is no smallest thing. The regress is benign because it does not entail any unacceptable result.

In cases where an infinite regress argument uses a benign regress, and only in those cases, the assessment of the truth of its regress formula is relevant to the cogency of the argument. ${ }^{48}$ For whenever a regress formula entails a vicious regress, the regress supports the final conclusion of an infinite regress argument by showing the formula to be unacceptable; and so the cogency of such a regress argument does not require that the formula be true. We simply examine whether the formula entails a vicious regress. However, the function of a benign infinite regress in an infinite regress argument is to support the final conclusion of the argument without showing the formula to be unacceptable; and so the argument is cogent only if the regress formula is true. Consequently, in order to evaluate the cogency of an infinite regress argument using a benign regress, we must address the issue of the truth of the regress formula.

I have used the labels "vicious" and "benign" to classify infinite regresses according to their logical function in an argument. There is another label worth introducing to describe some infinite regresses. A vicious or benign infinite regress is superfluous when it is not necessary to establish an intended conclusion. For example, a classic infinite regress is found in Plato's Third Man Argument (Parmenides, 131e-132d). An infinite regress of Forms of Largeness entails the statement that there are infinitely many Forms of Largeness. This result conflicts with Plato's theory of Forms, according to which there should be only one Form of Largeness. Thus, for Plato, the result is unacceptable, so the infinite regress is vicious, and hence, at least one of the statements that entail that regress is re- 
futed. However, from the second step of the regress it follows that there are two Forms of Largeness, and this result also conflicts with Plato's belief that there is only one such Form. Since for Plato this second result is also unacceptable, it suffices to refute the same statement that is refuted by the whole infinite regress. Since this second refutation takes place before any further entailment of the remainder of the regress, not all the infinite regress is necessary to refute that statement. Rather, every step after the second one is superfluous; thus, the infinite regress as such is superfluous.

In this paper I have attempted to explain some aspects of the nature of infinite regress arguments by discussing the structure and diagram of a typical infinite regress argument, and certain necessary conditions of an infinite regress. These conditions were expressed in hypothesis $\mathrm{H}$. I used $\mathrm{H}$ to show how certain regress formulas fail to entail an infinite regress; to discuss the risks of constructing a regress formula exclusively from the structure of given steps of an alleged regress; to evaluate the derivation of an alleged infinite regress in terms of the sufficient condition of each step of the regress; and to show that changes in the terms of an intended infinite regress can block the entailment of the regress. I have described how an infinite regress functions as a premise in an infinite regress argument, and explained a condition of cogency of an infinite regress argument that uses a benign regress.

Once upon a time an author sympathized with his readers because he new that they would have found it exceedingly stressful to read his dry paper. In order to relieve them of their stress, he decided to end his paper with a short cathartic story about an author who once upon a time, sympathized with his readers because he knew that they would have found it exceedingly stressful to read his dry paper. In order to relieve them of their stress, he decided to end his paper with a short cathartic story about ... ad infinitum. ${ }^{45}$

\section{Notes}

${ }^{1}$ The few publications on infinite regress arguments usually address specific issues that either do not apply to most infinite regress arguments, or do not facilitate our evaluation of most of them: Clark (1988), Day (1987), Gardner (1965), Gratton (1994, 1995), Johnstone (1989, 1991, 1994), Passmore(1970), Rosenberg (1978), Sanford (1984) Schlesinger(1983), YaldenThomas (1964).

2 I would like to thank Professors Derek Allen, Robert Tully, David Hitchcock, and two referees of this joumal for their constructive comments on earlier drafts of this paper.

${ }^{3}$ Gilbert Ryle (1968), pp. 31-32. My discussion of this passage is not intended to be a complete explanation and evaluation of the argument.

${ }^{4}$ Another statement that triggers the formula is, "There is at least one intelligent act, call it 'act,"." l choose the simpler statement in order to facilitate the discussion.

"For example, in Sextus Empiricus's Outlines of Pyrhonism the regress formula, "All things are [properly] defined by a definition, and all definitions are things", entails an infinite regress of definitions, which entails the unacceptable result, according to Sextus, that "we 
shall define nothing". Since we do and will define some things, the statement that "we shall define nothing" is false.

The results entailed by infinite regresses can be unacceptable for different reasons. In the passage 332b32-333a15 of On Generation and Corruption, Aristotle's regress is supposed to lead to the false and thus unacceptable consequence that "it will be impossible to define any element" (i.e. Earth, Water, Air, Fire), and that it will be "impossible for any [element] to come to be."

${ }^{6}$ For example, John F. Post (1980) proposes certain regresses of justification (p. 33) and explanation (p. 46), argues that they lead to absurdities, and then concludes that such regresses do not exist.

${ }^{7}$ This regress from Anaxagoras is found in J.M. Robinson (1968), p. 178.

${ }^{8}$ This regress from Zeno is found in H.D. Lee (1967), p. 37.

${ }^{9}$ A.R. Lacey (1990), p. 202.

${ }^{10}$ In this particular example, a term's having the name of the class to which belong all the terms of the regress is sufficient to satisfy the formula. However, in more complex formulas, a term might require more properties

"For example, consider the regress formula, for any $x$ and $y$ where $x$ is larger than $y$, there is a $z$ such that $y$ is larger than $z:(x)(y)(x \mathrm{~L} y \rightarrow(\mathrm{Ez})(y \mathrm{~L} z))$. In this case the triggering statements will have the form, $a \mathrm{~L} b, b \mathrm{~L} c, c \mathrm{~L} d$, etc., but each triggering statement is also a step. However, in most cases, the triggering statement and step in an output are distinct.

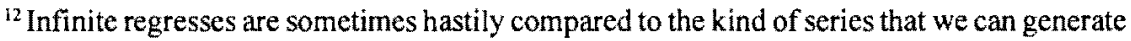
from the vagueness of a term; e.g., if I'm bald and an additional hair grows, I'm still bald; if I'm bald and a further hair grows, I'm still bald, etc. This comparison is mistaken for a number of reasons. First, the derivation of an infinite regress in an infinite regress argument does not rest on our inability to draw a line between vague terms (e.g., bald and not bald). Secondly, there is sometimes a mistaken inference from such a series that no successive accumulation of insignificant changes will amount to significant change (e.g., no successive accumulation of one hair to a bald head will make it not bald, no successive accumulation of one grain of sand to a heap will amount to a mountain); but there is no comparable mistaken reasoning in infinite regress arguments. Thirdly, the succession of insignificant changes cannot go to infinity, for one would reach a point where the accumulation would obviously amount to a significant change, and where the use of a vague term would not be disputable (e.g., I would not be bald if I had infinitely more hairs than a bald man); but a regress in an infinite regress argument typically must go to infinity.

${ }^{13}$ For a proof that most infinite regresses require infinitely many terms, see section 1.6 of my dissertation.

${ }^{14}$ This example illustrates that not every infinite series is an infinite regress. However, some genuine infinite regresses do have the same structure, $a \mathrm{R} b, a \mathrm{R} c, a \mathrm{R} d$, etc. For instance, 1 $<2,1<3,1<4,1<5$, etc. The regress formula is, for any natural number $x$ greater than 1 , there is a natural number $y$ equal to $x+1$, and 1 is less than $y:(x)[(\mathrm{N} x \& 1<x) \rightarrow$ $(\mathrm{E} y)(\mathrm{N} y \&(y=x+1) \& 1<y)]$.

Further examples of infinite series that are not infinite regresses include all infinite series ordered by a binary relation in which a term recurs, for no term can logically recur in an infinite regress ordered by such relations. For a proof of the latter claim, see Appendix $A$ of my dissertation. Hence, what generates an infinite series will not necessarily generate an infinite regress. Thus, we cannot assume that our understanding of infinite series will necessarily help us to understand the derivation of infinite regresses.

${ }^{15}$ See sections 1.3 and 1.4 of my dissertation.

${ }^{16}$ G.C. Nerlich (1960). 
${ }^{17}$ Republic, in Plato, The Collected Dialogues (1980), p. 822.

${ }^{18}$ Nerlich is similarly mistaken in believing that there is an infinite regress argument in the Timaeus $(31 a-b)$.

${ }^{19}$ D.C. Yalden-Thomson (1964).

${ }^{20}$ Sometimes we must examine the kind of relation that orders the terms of an intended regress. For a detailed discussion of this topic see the second chapter of my dissertation.

${ }^{21}$ William Poundstone (1990), p. 259.

${ }^{22}$ Colin McGinn (1990). My italics.

${ }^{23}$ Ibid. My boldface.

${ }^{24}$ This second reason illustrates why it is important to examine the binary relation that orders the terms of an infinite regress constructed from such relations. For example, the formula, "For any being $x$, there is a being $y$, and $y$ gives meaning to $x$ " can be true and yet fail to exclude the possibility that only a finite number of beings give meaning to one another; and so the formula fails to entail an infinite regress. But if the formula included the relation, " $y$ is greater than $x$," then, regardless of the respect to which $y$ is greater than $x$, the truth of the formula, "For any being $x$, there is a being $y, y$ is greater than $x$, and $y$ gives meaning to $x$," would exclude any possibility that only a finite number of beings give meaning to one another, and would thus entail two infinite regresses: $b$ is greater than $a, c$ is greater than $b$, ad infinitum; and $b$ gives meaning to $a, c$ gives meaning to $b$, ad infinitum,

${ }^{25}$ Patrick K. Barstable (1975), p. 368; John Passmore (1970), p. 31.

${ }^{26} \mathrm{~L}$. Wittgenstein (1972), p. 88.

${ }^{27}$ When Ayer (1973) says, "To avoid the regress we have to admit that some things have to be identified directly" (p.56), he is indirectly pointing out that this formula also rests on the debatable assumption that nothing could be identified directly.

${ }^{28}$ Wittgenstein makes a similar point at \#50 in the Philosophical Investigations, p. 25. However, some philosophers have expressed a concern for the difficulties that can arise when significant changes occur in the terms of an alleged regress. For example, see Hume's $(1947$, p. 160) infinite regress that extends from a material world to an ideal world. Since the material world and the first ideal world appear to be significantly different, Hume's attempt to establish the similarity between them suggests that he wants to avoid the difficulties of extending a regress from one domain of terms to a radically different domain of terms.

${ }^{29}$ Alan Donagan (1963), p. 226.

${ }^{30}$ Passmore (1970), p. 27.

${ }^{31}$ D. Jacquette and H.W. Johnstone (1989) make a similar point.

${ }^{32}$ Passmore (1970), p.28.

${ }^{33} \mathrm{~J}$.W. Salmond, Jurisprudence, 10th ed. (Glanville Williams) App.I, p. 490, quoted in Stanley I. Benn, "The Uses of 'Sovereignty", in Anthony Quinton, ed. (1971), p. 69, footnote no. 1.

${ }^{34}$ For an example, see Schlesinger (1983), p. 221.

${ }^{35}$ For a detailed discussion, see Chapter 6 of my dissertation. I have not examined these infinite regress arguments in this paper because I have found only a few, and my goal is to identify and clarify the characteristics common to most infinite regress arguments.

${ }^{36}$ Schlesinger (1983), p. 221.

${ }^{37} \mathrm{~A}$ famous example of such an infinite regress argument is McTaggart's (1921) regress argument against the reality of time, in Volume 2, Book 5, Chapter 33.

${ }^{38}$ For example, see J.L. Mackie 's (1965) regress argument against a theist's solution to the problem of evil. 
${ }^{39}$ One distinguishing feature of regresses of recurring problems and solutions is that they do not have to be infinite in order to entail such a conflict, for the conflict results after the first proposed solution. The word "regress" is used in such contexts when the same pattern of reasoning is extended beyond the appearance of the first conflict in order to derive further conflicts, and thus to make it clear that the proposed solution misfires.

${ }^{40}$ Romane Clark (1988).

${ }^{41}$ rbid, p. 374.

${ }^{42}$ Ibid., p. 372.

${ }^{43} \mathrm{Ibid}$, p. 372 , p. 374

${ }^{4}$ Ibid., p. 373

${ }^{45}$ The existence of benign regresses is overlooked by some philosophers. For example, "a genuine endless regress is evidence of the falsity of the conception which gives rise to it, [. .. ] I hold this on the ground that the endless regress always presupposes the self-contradictory purpose to sum an admittedly infinite series." A.E. Taylor (1961), p.156. Day (1987) also overlooks the distinction between vicious and benign regresses because the few arguments he examines use only vicious regresses.

${ }^{46}$ Outlines of Pyrrhonism, Book 2, 39-41, op. cit., p. 177.

${ }^{47}$ John Mansley Robinson (1968), p. 178.

${ }^{48}$ A regress formula consists of one or more universal statements (e.g., "Every place is in a place") and thus can be true or false.

${ }^{49}$ Is there an infinite regress here?

\section{REFERENCES}

Aristotle. 1985. The Complete Works of Aristotle. Jonathan Barnes (ed.). Princeton, N.J.: Princeton University Press.

Ayer, J.A. 1973. The Central Quesions of Philosophy. London: Weindenfeld \& Nicolson. Barstable, Patrick K.1975. Logic: Depth Grammar of Rationality. Dublin: Gill \& Macmillan.

Clark, Romane.1988. "Vicious Infinite Regress Arguments", Philosophical Perspective, 2, Epistemology, pp. 369-380.

Day, T. J. 1987. 'Infinite Regress Arguments." Philosophical Papers 16, pp. 155-163.

Donagan, Alan.1963. "Universal and Metaphysical Realism.” Monist 47.

Gardner, Martin. 1965. "Infinite Regress." Scientific American 212, April, pp. 128-132.

Gratton, C. 1994. "Circular Definitions, Circular Explanations, and Infinite Regresses." Argumentation 8, pp. 295-308.

- 1995a. Aspects of the Logic of Infinite Regress Arguments, Ph.D. dissertation, University of Toronto.

_. 1995b "Vicious infinite regresses and the inability to complete infinitely many tasks." In F.H. van Eemeren, R.Grootendorst, J.A. Blair, C.A. Willard, (eds.), Analysis and Evaluation, pp. 39-45. Amsterdam: SicSat.

Hume, David. 1947. Dialogues Concerning Natural Religion. Indianapolis \& New York: Bobbs Merrill.

Johnstone, H. W. 1991. "La r'gression ... l'infini et l'argumentum ad hominen." In Alain Lempereur, (ed.), L'Argumentation (Colloque de Cerisy), pp. 31-36. Liege: Mardaga. 


\section{Claude Gratton}

1994."Question-Begging and Infinite Regress." Argumentation 8, pp. 291-293.

Jacquette, D., and Johnstone, H.W. 1989. "Dualities of Self-non-Application and Infinite Regresses." Logique et Analyse 125-126, pp. 29-40.

Lacey, A.R. 1990. A Dictionary of Philosophy. London, New York: Routledge.

Lee, H.D. 1967. Zeno of Elea, A Text with Translation and Notes. Amsterdam: Adolf M. Haddert.

Mackie, J.L. 1965. "Evil and Omnipotence." Mind 65, pp. 200-212.

McGinn, Colin. 1990. Book review of The Meaning of Life and Other Essays by A.J. Ayer. London Review of Books, Vol. 12, No. 6.

McTaggart, J.M.E. 1921. The Nature of Existence. London: Cambridge University Press.

Nerlich, G.C. 1960. "Regress Arguments in Plato." Mind 69, pp. 88-90.

Passmore, J. 1970. Philosophical Reasoning. 2nd ed. London: Gerald Duckworth.

Plato, 1980. Plato. The Collected Dialogues E. Hamilton, H. Cairns (eds.). Princeton: Princeton University Press.

Post, John F. 1980. "Infinite Regresses of Justification and of Explanation." Philosophical Studies 38, pp. 31-52.

Poundstone, William. 1990. Labyrinths of Reason. New York: Anchor Books, Doubleday. Quinton, Anthony, (Ed.). 1971. Political Philosophy. Oxford: Oxford University Press.

J.M. Robinson, J.M. 1968. An Introduction to Early Greek Philosophy. Boston: Houghton Miffin.

Rosenberg, Jay, F. 1978. The Practice of Philosophy. A Handbook for Beginners. Englewood Cliffs, N.J: Prentice-Hall.

Ryle, Gilbert. 1968. The Concept of Mind. Harmondsworth, England: Penguin Books.

Sanford, David.1984. "Infinite Regress Arguments." In H.H. Fetzer (ed.), Principles of Philosophical Reasoning. Totowa, N.J.: Rowman and Allanheld.

Schlesinger, George.1983. Metaphysics, Methods and Problems. Totowa, NJ: Barnes and Nobles.

Sextus Empiricus. 1933. Outlines of Pyrrhonism. In Sextus Empiricus, Vol. 1, trans. R.G. Bury. London: William Heinemann Ltd, New York: G.P. Putman's Sons.

Smith, Quentin. 1986. "The Infinite Regress of Temporal Attributions." The Southern Journal of Philosophy 26, pp. 383-396.

Taylor, A.E. 1961. Elements of Metaphysics. London: Methuen.

Wittgenstein, L. 1972. Philosophical Investigations. Trans. G.E.M. Anscombe. Oxford: Basil Blackwell,

Yalden-Thomas, D.C. 1964. "Remarks about Philosophical Refutations." Monist 48, pp. 501-512.

Note: To assist in ongoing research, the author would welcome being informed of precise sources of infinite regress arguments.

CLAUDE GRATTON DEPARTMENT OF PHILOSOPHY

UNIVERSITY OF NEVADA, LAS VEGAS LAS VEGAS, NV 89154-5028 GRATTONCONEVADA.EDU 